\title{
ONZE BIER-ACCIJNS.
}

Ten gevolge van dringende verzoeken van het bestuur der $\mathrm{Ne}$ derlandsche Beijersch-bierbrouwerij heeft de minister van Financiën in het zittingjaar 1866-1867 een ontwerp ingediend dat; na eenige wijzigingen, wet is geworden als ${ }^{\text {wet }}$ van den $7^{\mathrm{n}}$ Julij 1867, houdende nadere bepalingen omtrent den accijns op de binnenlandsche bieren en azijnen." staatsbl. $\mathrm{n}^{0} .84$.

De $1^{e}$ alinea van het slotartikel dier wet luidt: „Deze wet blijft van kracht tot den 31" December 1870." Met het oog op deze bepaling komt het mij wenschelijk voor dat de belanghebbenden hunne meeningen openbaren over deze wet en het besluit van 12 Oct. 1867, Slaalsbl. $\mathrm{n}^{0}$. 106 tot uitroering van art. 1 on 2 der wet. Ik wil trachten duidelijk te maken wat, in mijn oog, het goede en verkeerde dier wet is, en hoop dat velen mijn voorbeeld zullen volgen. Wanneer eene belastingwet zoozeer ingrijpt in alle bijzonderheden der fabrikage als deze wet, is voorlichting hoogst noodig.

Om eenigzins verstaanbaar te zijn voor niet deskundigen is het nuttig vooraf iets te zeggen over de verschillende wijzen van bierbrouwen en van heffing der bierbelasting.

Het graan wordt tot mout gemaakt door het te doen kiemen. Daartoe wordt het geweekt, en als het den vereischten graad van vochtigheid verkregen heeft, aan hoopen gezet, die, tot behoud en verkrijging van de voor de kieming noodige, gelijkmatige warmte en rochtigheid, nu eens dikker, dan weder dunner gezet worden. Is de kieming ver genoeg gevorderd, dan wordt die door drooging afgebroken, de wortelkiemen worden van het mout gescheiden on het mout is gereed. Zal het eigenlijke brouwen nu plaats hebben, dan wordt het mout gemalen. Door infusie of decoctie, of door eene combinatie van beide methoden, worden uit het gemalen mout, alleen of vermengd met andere meelsoorten, de meeste oplosbare bestauddeelen gewonnen. Door infusie verstaat men behandeling met Econ 1869. 
heet water zonder kooking van het meel of van troebele, veel fijn meel bevattende, aftreksels.

Door decoctie, koking van het meel, hetzij dan slechts van de zeer fijne deelen zoo als zij in een troebel aftreksel bevat zijn, hetzij van een gedeelte van het in de roerknip (*) natgemaalte en van daar in den ketel overgebrachte meel, hetzij van een gedeelte meel dat droog in het water in den ketel uitgestort, daar langzamerhand verhit, gekookt en daarna bij het overige ondertusschen in de roerkuip met koud of heet water behandelde meel gevoegd wordt; hetzij eindelijk van al het meel, nadat het eerst in roerkuip of ketel met koud of heet water behandeld is en er een gedeelte vocht afgenamen is, :om, na de koking, er weder mede vereenigd te wonden om eene betere omzetting te verkrijgen. Men ziet dat er vele renschillende decoctie-methodon in gebruik zijn. Natuuarlijk i is die de beste welke het doel met de minste brandstoffen, thjid on arbeid het volkomenst bereikt. Ongelukkig is de meest algemeen in gebruik. zijnde decoctie-methode, eene der omslachtigste, en heeft het besluit van 12 Oct. 1867 die verondersteld alleapn in gebruik te zijn en de andere onmogelijk gemaakt. Doch hiervan later. - Heeft men alzoo het meel uitgebrouwen dan wardt het. verkregen vocht geklaard door filtratio over het uitgebrouwen meel, gekookt en daarbij met hop roorzien, afgekoeld tot de graden die voor de soopt ran gisting noodig. zijn en door vermenging met gist, in gisting gebracht, $\mathrm{Na}$ de gisting heeft men het. bier dat nu na korterẹn of langeren tijd gelegen te hebben en volkomen helder te zijn geworden, in consumtie wordt gebracht.

De voomnaamste wijzen waarop de belasting wordt geheven; zijn:

1. Van het.werktuig.

a. De roerkuip. Belgie, Rusland, Nederland (volgens de wet $\operatorname{van} 2$. Aug. $1822, S t b l . n^{\circ} 32$.)

b. De kelel. Frankrijk, Baden.

2. Van die grondstof.

a. De geweekte gerst. Engeland.

b. Het moul. Noorddnitsche Bond, Beijeren, Nederland (wet $\operatorname{van} 7$ Juli 1867, Stbl. $\mathbf{n}^{0}$ 84.)

a. Het mout en surrogaten van mout $d \dot{d} i_{\text {, }}$ alleriei zetneel-, dextrine-, suiker- en eiwithoudende stoffen. Wurtemberg.

(") De roer- of beslagkuip is de kuip waarin meel en water gemengd, geroerd, beslagen worden. Dikwijls is zij voorzien vau een tweeden, met gaatjes doorboorden bodem en is dan tevens klaringsknip. 
3. Van het product.

a. Het afgehoulde vocht vóón de vermenging met gist (wort) Costenrijk.

b. Het tot gebruik gereede bier. Fereenigde Staten.

In het algemeen mag gezegd worden dat de heffingen onder no 1 de slechtste; die onder $n^{\circ} 3$ de besto zija'.

Bij; de invoering der wet van 1822 zijn de belangen dex-brouwers in de noordelijke provinoiën opgeofferd am die hunnen beroepsgenpoten in de zuidelijke provinciën. Hogendorp motiveerde zijne stem voor het ontwerp aldus: „De bierbrouwerijen in de zuidelijke provinciën zijn, to zamen genomen, veel uitgebreider dan die in de: noordieligite, en uit dien hoofde stem ik garne too in de regeling van de belasting, die eerstgemelden het angenarmst is. " $\left({ }^{*}\right)$ Hoe hij overigens dacht over de versohillende wijze van beffing blijkt duidelijk uit de volgende aanhalingen :

${ }_{n}$ Wordt de nijverheid aan hare eigene werkzaamheden overgelaten, zoo maakt zij gedurige vorderiagen; de eene verbetering, de eene uitvinding volgt op de andere, en de kunst bereikt den haogsten trap. Maar de wet stremt deze vlugt; zij dwingt tot eene. treurige eenvonmigheid, en de middelmatigheid wordt de regel, dien men niet meer mag oversehrijden. Dit zijn de noodzakelijke gevolgen van het leggen der belasting op de brverking; en men kan die niet ontduiken, dan door den impost te verleggen op het bevaenhte."

"Men schrijft asn de belasting, als gevolg, eene opwekking der nijverheid toe, en men heeft gelijk; zoolang die belasting niet drukt dan op het fabrikaat. Maar zoodra zij de bexerking. (de fabrikaadje) aantast, en vaste regelmaten daarombrent voorschrijft, bluscht sij-de nijverheid uit, en elke volmaking, elke uitrinding die zij dan voortbrengt, dient om de belasting te antduiken. Verve van tot de vorderingen der kninst bij te dragen; dient de belasting op de fabrikaadje meermalen, om goede manieren van bewerking, die in gebruik zijn, aan verkeerde op te offeren, die de belasting minder drukkend maken." ( $f$ )

Na de scheiding van Belgie werd, ondanks herhaalde klachten, petitionnementen en verscheiden geschriften, niets gedasn tot ver. betering der wet op de bieren.

In 1855 werd, ten gevolge van de afschaffing van den accijps

(*) Bijdragen Deel VI blz. 233, onde uitgave.

(†) T. a. p. blz. $238,239$. 
op het gemaal, $\left(^{*}\right)$ een ontwerp tot wijziging ingediend. Dit kwam niet in behandeling en in 1856 werd een gewijzigd ontwerp ingediend, doch ingetrokken toen bij de Tweede Kamer groote neiging bleek te bestaan om bij deze gelegenheid den accijns op den azijn af te schaffen.

In 1863 werd een ontwerp van eene geheel nieuwe wet op de bieren ingediend, waarbij de accijns aanmerkelijk verhoogd zoude worden. Dit ontwerp rond weinig bijval $1^{\mathrm{u}}$ wegens de verhooging van den accijns, $2^{\circ}$ wegens de bevoorrechting der groote brouwerijen; het werd derhalve ingetrokken.

Voor brouwerijen, die wenschten to werken naar methoden die niet overeen kwamen met de bepalingen der wet van 1822 , werden bij administratieve beschikkingeu, afwijkingen toegestaan. Daar de regering dit niet bekend maakte was ongelijkkeid daarvan het gevolg, want het was toeval als men ontdekte dat die vergunningen tot afwijkingen van de wel te verkrijgen waren. De accijns werd ongeveer $50 \mathrm{pCt}$. hooger wanneer men met zulk eene vergunning werkte. Bij de aanwending van de decoctie-methode zonder vergunning werd de accijns van 300 tot 400 pCt. hooger. De Nederlandsche Beijersch-bierbrouwerij heett den tijd, waarin zij gebrouwen heeft, vóór de in werking treding der wet van 7 Juli 1867 en van het besluit van 12 Oct. 1867 (3 à 4 maanden) ook met zulk eene vergunning gewerkt.

Bij deze onderneming schijnen invloedrijke personen betrokken te zijn; zeker is het dat zulk een' krachtige drang werd uitgeoefend, dat zeer spoedig verkregen werd wat jaren achtereen te vergeefs gevraagd was.

Ook zal bij de beschouwing van genoemde wet en besluit herhaaldelijk blijken dat zij vooral met het oog op de behoeften en wenschen dier inrichting rijn opgesteld.

De wet bestaat uit slechts 5 , het besluit uit 39 axtikels.

De wet stelt dan ook alleen beginselen vast. In art. 1 dat de accijns, op verlangen des brouwers, kan geheven worden naar den maatstaf van drie en een halven cent per pond gewoon ruw moutmeel; dat bij het gebruik van ander ruw of ongebuild meel, of van gebroken of ongebroken graan, daarvoor dezelfde accijns ver-

(*) Het mout, dat naar den molen gebracht werd, moest gedekt zijn door consentljiljetten; deze moesten bewaard worden on werden dan vergeleken met de aangiften tot brouwen, zoodat daardoor éene controle werd, uitgeoefend die echter weinig te beduiden had, waut bij smokkclarij moesten natuurlijk beiden vervallen. 
schuldigd is; dat, indien eene andere voor de wijngisting geschikte grondstof dan graan wordt gebruikt, de accijns mede kan geheven worden tot het voormelde bedrag voor eene hoeveelheid grondstof welke evenveol alcohol kan opleveren als een pond gewoon ruw moutmeel; dat de bepalingen noodig voor de heffing volgens dit artikel, bij koninklijk besluit worden vastgesteld; in art. 2 dat, onder de noodige bepalingen tegen misbruik, ook andere afwijkingen kunnen toegestaan worden van de wettelijke voorschriften, wanneer dit in het belang van den betrokken tak van nijverheid noodig blijkt; dat deze afwijkingen zich echter niet uitstrekken tot het bedrag en den grondslag van den accijns; in art. 3 , dat de bepalingen bij art. 1 en 2 bedoeld worden rastgesteld bij algemeenen maatregel van inwendig bestuur (*) en van toepassing zijn op alle fabriekanten die dit blijkens schriftelijke verklaring, verlangen; in art. 4, dat overtredingen gestraft zullen worden met boeten van vijftig tot vier honderd gulden; in art 5 , dat de wet van kracht blijft tot 31 Dec. 1870.

Het besluit is verdeeld in zes hoofdstukken; het eerste bevat, in twee artikels, voorsthriften omtrent de verklaringen die de brouwer heeft in te leveren als hij volgens deze wet en besluit wil werken. Het tweede bevat de bepalingen omtrent de heffing op het verbruikte meel of graan in niet minder dan 22 artikels. Het derde geeft in vier artikels de voorschriften voor het beverken van meelspecièn in ketels. Het vierde handelt over de inhoudsruimte der roerkuipen, het vijfde over overschrijoing van crediet en over uitvoer naar buiten 's lands, het zesde over documenten tot vervoer van bier of azijn.

Over het eerste en de drie laatste hoofdstukken heb ik niets te zeggen, maar tegen verschillende artikels van het tweede, en vooral tegen het derde hoofdstuk heb ik vele bezwaren.

In de tweede alinea van art. 6 wordt bepaald dat, als de aftreksels op de koelbakken niet tijdig genoeg zijn afgekoeld, de bierbrouwer het tijdsverloop, aangegeven voor het overbrengen dier aftreksels in geilof gistkuipen, met hoogstens twee uren kan verlengen. Van vervroeging is echter geen sprake en dit kan toch in ons veranderlijk klimaat evenzeer noodig zijn. De brouwer moet, vóór het begin van het brouwsel, eene arngifte doen warin al de verschillende tijdstippen

(*) Dit is eene hoogst nuttige verbetering, door de Tweede Kamer aangebracht. Zonder deze zouden weder dezelfde ongelijkheden ontstaan zijn als vroeger door de vergunningen bij administratieve beschịkking. 
der werkzaamheden moeten opgegeven worden. Een brouwsel duurt van acht tot zestien uren behalve de afkoeling. Hoe dikwijls gebeurt het nu dat het weder verandert; de wind draait of sterker wordt, en daardoor de afkoeling plaats heeft in 4 aे 5 uren, in pleats van 6 à 8 uren zoo als de brouwer bij de angifte berekend heeft, hij mag de kraan van den koelbak niet losdraaijen, do wort komt onder de gewenschte graden en maakt eene abrormale gisting.

D.e eerste alinea van art. 7 luidt: „Er kan geene aangifte tot „brouwen op den roet van dit hoofdstuk worden gedaan voor eene "geringere hoeveelheid meel of graan dan van vier honderd pond „per brouwsel." Door deze bepaling worden dus al de kleine brouwers die minder dan $400 \mathrm{Ned}$. pd. verwerken van het gebruik van deze wet uitgesloten en tot die van 1822 bepaald. Dit is onbillijk en ik geloof niet te veel te zeggen als ik beweer dat de Tweede Kamer zulk eene bepaling niet zoude geduld hebben als die aan hare goedkeuring was onderworpen geworden, want de tegenstand tegen het ontwerp van 1863 werd vooral veroorzaskt door een dergelijk voorsehrift. De regeering verkeert zeer in dwaling als zij meent dat de belangen der schatkist bij de wet-van 1822 beter gewaarborgd zijn dan bij de heffing van het meel. De 2e alinea is ${ }^{\mathrm{e}} \mathrm{De}$ $n^{\text {alan }}$ te geven hoeveelheid moet roorts minstens een en twointig "pond per vat inhoudsruimte der te bezigen roerkuip bedragen; ,indien de grondstof alleen in die kuip bewerkt wordt, en minstens neertien pond indien op den voet van het volgend hoofdstuk wordt "gewerkt." Wonderlijke bepaling vourwaar, en die weinig zaakkennis verraadt bij de opstellers en adviseurs. Het is toch bekend dat de gewenschte omzettingen van zetmeel in dextrine en suiker, sneller en beter plaats vinden bij eeve ruime dan bij eene geringe hoereelheid water. Evenzeer is het bekend dat die omzettingen slechts. tot stand komen onder den invloed van zekere temperaturen en waar is men nu meer meester van de temperaturen: in den ketel, waaronder men het vuur vermeerderen of versterken kan, of in de kuip, waar men de temperatuur verkrijgt door vermenging van het meel met het water en, als eenmaal de kuip vol is, an de temperațuur niet meer veranderen kan?.

Art. 9. $1^{\text {o }}$ alinea kan bij het gebruilk van verschillende soorten van meel lastig worden en aanleiding geven dat men een groot aantal zakken, ieder met eene kleine hoeveelheid verkrijgt, wat èn, voor den brouwer, èn voor de ambtenaren niet gemakkelijk is. Het gemak van de ambtenaren zal toch wel het doel zijn van deze kleingeestige bepaling. 
De $2_{\mathrm{e}}$ alinéa is waarschijnlijks eene concessio aan de Nederlaridsche Beijersch-bierbrouwerij.

Bij art: $142^{\circ}$ alinea wordt het maximúm fan den tijd vobr do werkzaamheden in de roerkuip tóegestarn bij att. 18 der wet van 1822, met een vijfde vermin'derd. Ik kdn dit niet goedkeirten en evenzoo vind ik den tijd, bepaald aan het sl'bt van art. 28," wel wat kort. Men bedenke toch dat het uitloogen van de làtste hoeveelheden extract vit het meel veel tija vordert. Het hoete widter moet zeet langzagm door hèt meel dringen òn werking tè kuhno'en dơn. Haast men hierbij, dan blijft ex extrabt in den draf; dat ilóg kan geworinen worden en krijgt inen, wat nóg erger is; allicht troebele wort in den ketel.

Art. 20 verbiedt in de 1 elinea óm andefe gróndstoffen dán de daartoe aangegevene to verwerken of bij te voegen.

De $2^{\text {o }}$ alinea verbiedt in te slàan of voorhanden te kebbien in eene in werking żijnde bierbrouwerij; of in de panden welke dairtoe behooren of gemeenschap daarmede hébben, eenige suiker, stroop, honig, melasise of welke suikersappen ook behalvé ruwe, geraffineerde en gebrande riet- of beetwortelsuiker en voorts hoogistens

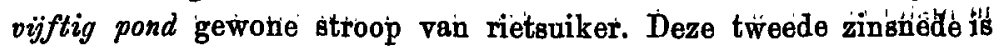
streng, maar de regering zal misśchien zeer geldige redènen hẻbben voor deze diaconische bepaling, hoewel zij in de memorie van beantwoording verklaarde: "Zoover bekend is wordt hier te lande igeèn melassie, aardappelstrioop of andere soortgelijke grondstof tot „vervaardiging van bier gebruikt." Jamimer is het dat niet is toegestarn jaarlijks eevie getringè hoeveelheid vruchtensuiker in to slan. $\mathrm{Zij}$ is de meest geschikte stof tot verjonging van belegen bier (lagerbier) dat te veel vergist is. Rietsuiker is veel minder geschikt, omdat die, voordat zij vergistbaar is, eerst in vruchtensuiker overgaat, waarbij steeds melkzuur gevormd wordt.

De 1o alinea vdn art. 21 geeft eene geheel onnoodig ruime bevoegdheid tot visitatie aan de ambtenaren. Daaruit kunnen eindelooże chicanes ontstán.

De $1^{\mathrm{e}}$ alinea van art. 22 koüt mij voor volkơmen overitollig te zijn en slechts to herhalen wat reeds in de $2^{\text {le }}$ alinea van airt. 6 vootgesechreven is.

Art. 25 is, in tijin oog, wel het ongelukkigste artikel van do gétieèle wet. Daardoor toch word̆ s'lèch'ts énè decoctie-methode mogelijk gemaakt, die nl. waarbij een gedeelte van de meelpap trt do rberkuip narar den ketel wordt overgebracht; daat gekoolkt en weder in de roerkuip teriggebracht enz: enż., de oúdé en nog zeer alge- 
meen in gebruik zijnde Munchener, alt-baijerische methode, de wereldbekende heen en weersleeperij van twee Dickmaische en een Lautermaisch. Natuurlijk zijn hier te lande weinig brouwerijen ingericht voor die Munchener methode, en zoo hebben dan ook, tot nog toe, zeer weinig brouwers gebruik gemaakt van de nieuwe wet, (*) maar dit is het noodzakelijke gevolg van art. 7 en art. 25.

Balling, Philip Heisz, Habich en anderen hebben in hunne werken en tijdschriften verschillende meer rationele decoctie-methoden beschreven en aanbevolen, zoodat bijna iedere brouwer, welke ook de inrichting zijner brouwerij zij, zijne gading zoude kunnen vinden, als de wet hier niet zoo ergerlijk ontwikkeling en vooruitgang tegenhield. Het overbrengen en verwarmen (niet koken?) in den ketel wordt bij art. 25 slechts toegestaan onder vijf voorwaarden, a, b, c, d en e, waarvan b, mijns inziens, volstrekt onnoodig is wegens het bepaalde in $c$; bij $d$ moet waarschijnlijk aan eene vergissing gedacht worden, want dit geeft slechts één uur tijd voor werkzaamheden, die minstens van drie tot acht uren vorderen. Terstond na de uitvaardiging der wet heeft dan ook eene ministerieele resolutie hierin wijziging moeten brengen.

Boven zeide ik dat van de drie voornaamste wijzen van heffing : naar het werktuig, de grondstof en het fabrikaat, de eerste de slechtste, en de laatste de beste is. Het z\&l wel duidelijk zijn dat de eerste het meest en de laatste het minst in de fabrikage moet ingrijpen. Zoo heeft de wet van 1822 tot noodzakelijk gevolg dat de brouwer om de vaste som belasting van de inhoudsruimte der roerkuip over zooveel bier, als mogelijk is, te verdeelen, zooveel meel in die belaste ruimte verwerkt als slechts gesehieden kan. Hierdoor wordt de hoeveelheid water veel te klein. Wilde de brouwer ook slechts de minste hoeveelheid water gebruiken die eene rationeele methode vereischt, dan zoude het bier enorm hoog belast worden en hij dus niet kunnen concurreren. Zoo is dan hier de wet de oorzaak van een geheel verkeerde methode, en heeft daardoor in een tak van industrie gedurende eene reeks van jaren alle ontwikkeling en rerbetering belet.

Fene belasting van de grondstof heeft ook zeer groote bezwaren, want hoevele grondstoffen van bier zijn er niet? Men moet dus, zooals bij de wet van 7 Juli 1867 reeds gedaan is, het gebruik

$\left({ }^{*}\right) 25$ bierbrouwerijen naar de heffing van het meel; 15 volgens het $4 \mathrm{e}$ hoofdstuk van het besluit. Staatsbegrooting 1869 , bijblad blz. 643 . 
van slechts eenige soorten toclaten en dus weder de nijverheid zeer aan banden leggen of de wetgeving wordt hoogst moeijelijk, ja bijna onmogelijk. Hier zoude de Wurtembergsche wet geraadpleegd moeten worden.

Bij de heffing van het produot, het fabrikaat, vervallen deze bezwaren. De nijverheid blijft geheel vrij en de administratio behoeft zich niet te verdiepen in al de bijzonderheden der fabrikage, waarvan zij toch nimmer geheel op de hoogte kan komen; met de opneming der aftreksels vóór de gisting zijn de ambtenaren, sedert de nieuwe wet in werking is, bekend geworden en dat is de wijze waarop bij het Oostenrijksche stelsel de belasting geheven wordt.

Het Amerikaansche stelsel, heffing bij den uitslag, is hier te lande in de vorige eeuw (tot 1806) in gebruik geweest. Het verdient in sommige opzichten de voorkeur. Zoo heeft de brouwer bij heffing bij den uitslag minder kapitaal noodig voor den accijns dan bij eenig ander stelsel, en hij loopt geen gevaar van ook nog den accijns te verliezen van bier dat door lekkage, verzuring of anderzins verloren gaat.

Mocht de regeering vasthouden aan de heffing van de grondstof dan is het te wenschen dat, even als in Wurtemberg, het gebruik van allerlei grondstoffen word't toegelaten.

Vooral dienen art. 7 en art. 25 te worden afgeschaft, want de kleinere brouwerijen hebben veeleer behoefte aan bescherming dan dat zij terugzetting kunnen lijden. De ondervinding, vooral in Duitschland, leert toch dat zij de concurrentie tegen de inrichtingen op groote scharl niet kunnen volhouden, $\left(^{*}\right)$ en toch zijn die kleine brouwerijen voor den landbouw hoogst weldadig. In Duitschland begrijpt men dit zoo goed, dat in den laatsten tijd gedurig over dit onderwerp geschreven is en de architecten en technici zich moeite geven om inrichtingen en methoden te vinden waardoor de kleine fabrieken beter met de groote zullen kunnen mededingen.

Geen bepaling van een minimum, toelating van alle grondstoffen en methoden, ziedaar de noodzakelijke voorwaarden voor eene gezonde en krachtige ontwikkeling van alle brouwerijen en tevens voor een' goedkoopen en deugdzamen volksdrank. Voor de kleine inrichtingen

(*) In Munchen waren in 1837 nog 38 brouwerijen; in 1857 was het getal verminderd tot 18 , en thans zijn er 15 , terwijl de hoeveelheid bier, die er geproduceerd wordt, bijna viermaal grooter is dan in 1837 .

In Pruissen is bet getal brouwerijen in de laatste 20 jaren bijna met de helft verminderd en de productie van bies daarentegen verbazend toegenomen, 
zijn zij voorwaarden van bestaan zonder welke zij onvermijdelijk langzamerhand te niet gaan, tot groote schade van veel meer belangen dan die der eigenaars.

Konde de Regeering besluiten tot overneming wit de Noordduitsche wet van de betaling bij abonnement (fixation) dan żoude daarmede aan alle eerlijke fabrikanten een' groote dienst bewezen worden. Strenge bepalingen verhinderen niet altijd het sluiken, maar kwellen de eerlijke industrieelen uitermate en de preníe die eene belastingwet op een' tak van nijverheid, om zoo te zeggen, aan de smokkelaars verleent; wordt soms grooter naarmate de wet strenger is. Bij zeer strenge bepalingen worden de eerlijke lieden vän die nijverheid afgeschrikt, en de Regeering heeft dan ten slotte alleen te doen met menschen van minder nauwgezette conscientie.

G GMBRINUS JunioR. 